Schicks, J., Pan, M., Giese, R., Poser, M., Ismail, N. A., Luzi-Helbing, M., Bleisteiner, B., Lenz, C. (2020): A new high-pressure cell for systematic in situ investigations of micro-scale processes in gas hydrates using confocal micro-Raman spectroscopy. - Review of Scientific Instruments, 91, 11, 115103.

https://doi.org/10.1063/5.0013138 


\section{A new high-pressure cell for systematic in situ investigations of micro-scale processes in gas hydrates using confocal micro- Raman spectroscopy}

Cite as: Rev. Sci. Instrum. 91, 115103 (2020); https://doi.org/10.1063/5.0013138

Submitted: 11 May 2020 . Accepted: 29 October 2020 . Published Online: 11 November 2020

(iD) Judith M. Schicks, Mengdi Pan, Ronny Giese, Mathias Poser, Nur Aminatulmimi Ismail, Manja Luzi-Helbing, Bernd Bleisteiner, and Christoph Lenz

为

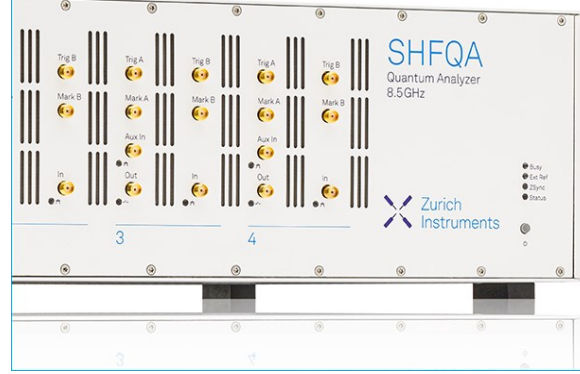

\section{Learn how to perform \\ the readout of up \\ to 64 qubits in parallel \\ With the next generation \\ of quantum analyzers \\ on November 17th}




\title{
A new high-pressure cell for systematic in situ investigations of micro-scale processes in gas hydrates using confocal micro-Raman spectroscopy
}

\author{
Cite as: Rev. Sci. Instrum. 91, 115103 (2020); doi: 10.1063/5.0013138 \\ Submitted: 11 May 2020 - Accepted: 29 October 2020 • \\ Published Online: 11 November 2020
}

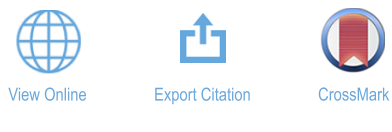

Judith M. Schicks, ${ }^{1, a)}$ (D) Mengdi Pan, ${ }^{1}$ Ronny Giese, ${ }^{1}$ Mathias Poser, ${ }^{1}$ Nur Aminatulmimi Ismail, ${ }^{1,2}$ Manja Luzi-Helbing, ${ }^{1}$ Bernd Bleisteiner, ${ }^{3}$ and Christoph Lenz ${ }^{3}$

\begin{abstract}
AFFILIATIONS
${ }^{1}$ GFZ German Research Centre for Geosciences, Telegrafenberg, 14473 Potsdam, Germany

${ }^{2}$ Center for Hydrate Research, Chemical and Biological Engineering Department, Colorado School of Mines, 1500 IIlinois Street, Golden, Colorado 80401, USA

${ }^{3}$ HORIBA Scientific, Neuhofstr. 9, 64625 Bensheim, Germany
\end{abstract}

a) Author to whom correspondence should be addressed: schick@gfz-potsdam.de. Telephone: +49-331-2881487

\begin{abstract}
Natural gas hydrates are ice-like solids composed of gas and water molecules. They are found worldwide at all continental margins as well as in permafrost regions. Depending on the source of the enclathrated gas molecules, natural gas hydrates may occur as coexisting phases with different structures containing predominantly $\mathrm{CH}_{4}$, but also a variety of hydrocarbons, $\mathrm{CO}_{2}$ or $\mathrm{H}_{2} \mathrm{~S}$. For a better understanding of these complex hydrate formation processes on a micrometer level, an experimental setup with a new high-pressure cell was developed, which can be used in a pressure range between $0.1 \mathrm{MPa}$ and $10.0 \mathrm{MPa}$. Peltier elements ensure precise cooling of the cell in a temperature range between $243 \mathrm{~K}$ and $300 \mathrm{~K}$. The selected temperature and pressure ranges in which the cell can be used make it possible to simulate the formation of gas hydrates in their natural environment, e.g., on continental margins or in permafrost areas at a depth of up to $1000 \mathrm{~m}$. The cell body is made of Hastelloy, which generally also allows the use of corrosive gases, such as $\mathrm{H}_{2} \mathrm{~S}$, in the experiments. The inner sample space has a volume of about $550 \mu \mathrm{l}$. A quartz window allows for microscopic observations and the systematic and continuous in situ Raman spectroscopic investigations of the forming hydrate phase mimicking natural conditions. Single point measurements, line scans, and area maps provide information on spatial heterogeneities regarding compositions and cage occupancies. The pressure cell can be operated as a closed system or as an open system with a defined continuous gas flow. The use of a continuous gas flow also allows for the in situ investigation of transformation processes induced by changes of the feed gas composition. In this paper, all details of the new experimental setup as well as preliminary results of our investigations on the formation of complex mixed hydrate systems both in the open and closed systems as well as the $\mathrm{CH}_{4}-\mathrm{CO}_{2}$ transformation process are presented.
\end{abstract}

Published under license by AIP Publishing. https://doi.org/10.1063/5.0013138

\section{INTRODUCTION}

Gas hydrates are ice-like, crystalline, and non-stoichiometric solids composed of water and gas molecules. ${ }^{1}$ Via hydrogen bonds, water molecules form well-defined cavities, which are stabilized by the inclusion of gas molecules. Natural gas hydrates contain predominantly $\mathrm{CH}_{4}$, but, as a function of the source and thus the composition of the feed gas, they may also contain $\mathrm{CO}_{2}, \mathrm{H}_{2} \mathrm{~S}$, or larger hydrocarbons. Depending on the size of the guest molecules, cavities of different sizes form and combine to unit cells of hydrates with structure I, II, or $\mathrm{H}$, which have all been verified in samples taken from natural gas hydrate occurrences. The formation of gas hydrates from a gas mixture may result in the coexistence of hydrate crystals with different compositions and structures. This has been 
reported by Lu et al. ${ }^{2}$ from natural gas hydrate samples recovered from the Cascadian margin by Klapp et al. ${ }^{3,4}$ who analyzed hydrate samples from the Chapopote Knoll and the Bush Hill area in the southern Gulf of Mexico, and recently by Wei et al. ${ }^{5}$ who characterized gas hydrate samples from the Shenhu Sea Area in the South China Sea, as well as Jin et al. ${ }^{6}$ who detected the coexistence of two sI hydrates with different textures and compositions in natural gas hydrate samples recovered from the Umitaka Spur in the Joetsu Basin, Japan. Even natural gas hydrate samples from Lake Baikal showed coexisting hydrate phases with different structures and compositions. The above-mentioned authors used different characterization methods, such as powder x-ray diffraction, to verify the different structures of the coexisting hydrate phases. For the determination of the varying compositions of the respective hydrate phase, they applied gas chromatography, solid-state nuclear magnetic resonance (NMR) measurements, and/or Raman spectroscopy.

Raman spectroscopy is a powerful tool to determine the overall composition and the cage occupancy of a hydrate phase. This technique enables us to distinguish between guest molecules in the free gas or liquid phase, encased into a clathrate cavity or dissolved in an aqueous phase. This is possible because the position of the Raman band of the respective gas molecules clearly shifts to different wavenumbers. In addition, the bandwidth (full-width at half-maximum) is significantly higher for those gas molecules dissolved into the water phase or enclathrated into a hydrate cavity. ${ }^{8-12}$ For instance, small gas molecules, such as $\mathrm{CH}_{4}$, do not only occupy one cavity type in the hydrate structure. They may be encased into both small cavities (pentagonal dodecahedra $5^{12}$ ) and large cavities (tetrakaidecahedron, $5^{12} 6^{2}$ ) of a structure I hydrate. The Raman spectra of a $\mathrm{CH}_{4}$ hydrate show, therefore, one prominent signal for the $\mathrm{CH}_{4}$ molecule encased into the large cavities at $2905 \mathrm{~cm}^{-1}$ and another band at $2915 \mathrm{~cm}^{-1}$, representing the $\mathrm{CH}_{4}$ molecule encased into the small cavities of structure I. The position of the Raman band for $\mathrm{CH}_{4}$ dissolved into an aqueous phase, however, is at $2910 \mathrm{~cm}^{-1}$, whereas the position of gaseous $\mathrm{CH}_{4}$ is at $2917 \mathrm{~cm}^{-1}$.

Raman spectroscopic measurements on natural gas hydrate samples and synthesized gas hydrates are usually single point measurements providing a more general verification of varying hydrate compositions and coexisting phases. ${ }^{3,5}$ The combination of Raman spectroscopy and confocal microscopy allows for the determination of spatially resolved gas hydrate compositions in three dimensions with resolution on a micrometer scale. Advanced mapping tools enable us to determine heterogeneities in composition, concentration gradients, and cage occupancy even within clear hydrate crystals suggesting the presence of single crystals. ${ }^{13}$ This has been documented, e.g., for a gas hydrate sample recovered in 2002 from gas hydrate outcrops on the seafloor in Barkley Canyon (northern Cascadia margin). A hyperspectral map across the hydrate crystal with the spectral region between $2800 \mathrm{~cm}^{-1}$ and $3000 \mathrm{~cm}^{-1}$ clearly indicated an inhomogeneous distribution of the guest molecules $\mathrm{CH}_{4}$, $\mathrm{C}_{2} \mathrm{H}_{6}$, and $\mathrm{C}_{3} \mathrm{H}_{8}$ within the scanned area. ${ }^{14}$

The reasons for the coexistence of hydrate phases with different structures and composition or strong heterogeneities in compositions within a hydrate crystal formed in a natural environment can be diverse and are not yet completely clarified. Depending on the local conditions, a possible explanation may be fluctuations of the composition of the feed gas flux from deeper sources or a fractionation of the gas in shallower sediments as a result of $\mathrm{CH}_{4}$ consumption and/or $\mathrm{H}_{2} \mathrm{~S}$ production due to biological processes, such as the anaerobic oxidation of $\mathrm{CH}_{4} \cdot{ }^{4,13}$ In some cases, the migration of the feed gas is limited and the local conditions can be described as a "closed system." Since some gases are preferentially encased into the hydrate structure compared to $\mathrm{CH}_{4},{ }^{15}$ the hydrate formation process may induce a fractionation of the feed gas and may result in the formation of coexisting hydrate phases with changing compositions in accordance with the changing feed gas composition. ${ }^{6}$ Another possible approach to explain these observations is to consider different hydrate formation kinetics: the formation of $\mathrm{CH}_{4}$ hydrate seems to be kinetically preferred compared to the formation of mixed hydrates. ${ }^{16}$ This, however, is only a selection of possible formation scenarios. For other locations, such as the Lake Baikal, other theories for the formation of coexisting hydrate phases are discussed. ${ }^{17,18}$

Since the formation processes of complex hydrate systems in nature are not yet fully clarified, further investigations are needed. For this purpose, an experimental setup is required, which enables the in situ investigation of the hydrate phase during the formation process. In recent years, a large number of different pressure cells have been developed in which gas hydrates can be formed and investigated using in situ Raman spectroscopy. In addition to relatively simple pressure cells with an optical window made of quartz, sapphire, or diamond, ${ }^{19-21}$ piston cells with variable volumes, ${ }^{22}$ capillary cells, $^{23}$ as well as diamond ${ }^{24,25}$ and sapphire anvil cells ${ }^{26}$ were developed and applied for the investigations of gas hydrates. All of these different cell designs are, however, only of limited suitability for investigating the formation of complex, heterogeneous, and coexisting gas hydrate phases under natural conditions. In order to be able to mimic some natural boundary conditions, the gas flow in the cell must be varied in a defined manner or the composition must be changed over time. Therefore, an ideal experimental setup should allow us to adjust and measure defined variations of gas fluctuations and changes of the feed gas composition. In this study, we introduce a new experimental setup with a custom-made, high-pressure flow-through cell combined with a high-resolution confocal Raman spectrometer, which enables the experimental implementation of natural hydrate formation processes. Preliminary results show that this experimental setup allows for in situ investigations of hydrate formation and transformation processes on a sub- $\mu \mathrm{m}$ to $\mu \mathrm{m}$ level in complex multiphase systems.

\section{EXPERIMENTAL SETUP}

\section{A. Raman spectrometer}

Raman spectroscopic measurements were performed using a LabRAM HR Evolution dispersive Raman spectrometer from Horiba Scientific coupled to an open microscope Olympus BXFM. The Raman spectrometer is equipped with two gratings 1800 grooves $/ \mathrm{mm}$ and 600 grooves $/ \mathrm{mm}$ and two laser sources: one frequency-doubled $\mathrm{Nd}$ :YAG solid-state laser with an output power of $100 \mathrm{~mW}$ (max. 48 mW at the sample surface) working at $532 \mathrm{~nm}$ and one wavelength-stabilized laser diode working at $785 \mathrm{~nm}$ with an output power of $300 \mathrm{~mW}$ ( $\max . \sim 150 \mathrm{~mW}$ at the sample surface). Respective edge filters are used to suppress the excitation lasers in the 
analyzing beam path with a cutoff at $\sim 50 \mathrm{~cm}^{-1}$. With a focal length of $800 \mathrm{~mm}$, this spectrometer achieves a maximum spectral resolution (grating 1800 grooves $/ \mathrm{mm})$ of $0.5 \mathrm{~cm}^{-1}(532 \mathrm{~nm})$ and $0.2 \mathrm{~cm}^{-1}$ $(785 \mathrm{~nm})$, respectively. A motorized pinhole in the analyzing beam path enables us to variably optimize the spatial resolution of the laser-spot measurements. Using, e.g., a 100× Olympus MPlan (NA $=0.9$ ) objective, the maximum spatial resolution in the $x-y$ direction is $\sim 0.5 \mu \mathrm{m}$ and $\sim 1.5 \mu \mathrm{m}$ in the $\mathrm{z}$ direction. For this study, however, a long-working distance objective (Olympus LMplanFLN 20×, NA $=0.4$ ) was used that has an optimum spatial resolution of $1.6 \mu \mathrm{m}$ in planar and $6.2 \mu \mathrm{m}$ in the $\mathrm{z}$ direction using a $532 \mathrm{~nm}$ excitation laser, respectively.

A special feature of this Raman spectrometer system is the motorized, software controlled, Märzhauser Scan+ sample stage attached to the microscope. The smallest step size in the $x-y$ dimension is $50 \mathrm{~nm}$ with a reproducibility of $1 \mu \mathrm{m}$ and an accuracy of \pm 1 $\mu \mathrm{m}$. The smallest step size in the $\mathrm{z}$ direction is $10 \mathrm{~nm}$. Since gas hydrate samples usually do not have an even, planar surface, it is important to ensure that the laser beam is focused on the sample surface during line scans or hyperspectral mapping. An automated focus system, using a dedicated software module (ViewSharp ${ }^{\mathrm{TM}}$ ) developed by Horiba Scientific, estimates the sample topography within the selected surface area prior to the mapping process and thus allows the laser beam to remain focused during the entire mapping acquisition.

Since the weight-loading capacity of the motorized sample stage is limited to ensure accurate function, a small and lightweight pressure cell had to be developed. The details are discussed in Sec. II B.

\section{B. Cell design}

The pressure cell has to fulfill certain requirements needed for the successful conduction of experiments investigating the formation and transformation processes of complex gas hydrate phases simulating different natural processes:

(1) To mimic the fluctuations of the composition of the feed gas flux, the composition of the gas phase in the sample cell has to be changed without changing pressure or temperature. This requires a continuous gas flow at constant and defined pressure and temperature conditions with an adjustable composition of the feed gas.

(2) If the experimental conditions are adapted to mimic a limited gas flow, the possibility to reduce or interrupt the continuous gas flow is needed. In addition, the changes in the composition of the hydrate phase and the coexisting gas phase need to be analyzed in situ.

(3) To avoid temperature gradients, the volume of the sample chamber should be small and the sample should be consistently cooled. A fast and selective tempering of the cell is advantageous.

(4) The incoming gas should be cooled before entering the sample area to avoid any heating effects and temperature gradients.

(5) A transparent optical window is necessary for microscopic investigation and in situ Raman spectroscopic measurements.

(6) The material of the sample cell requires high corrosion resistance at variable experimental conditions.

(7) Since the manufacturer of the motorized sample stage recommends not exceeding a load of about $500 \mathrm{~g}$ for its standard configuration, the weight of the pressure cell is limited.

(8) Due to the limited distance between the objective and the sample stage $(60 \mathrm{~mm})$, the height of the cell including the cooling system is limited to $\sim 30 \mathrm{~mm}$.

The body of the new pressure cell (Fig. 1) designed and built at GFZ is made of Hastelloy, to ensure maximum corrosion resistance even if corrosive gases, such as $\mathrm{H}_{2} \mathrm{~S}$, are used. The outer dimensions of the pressure cell are $50 \times 50 \times 14 \mathrm{~mm}^{3}$. The cell may be operated at pressures up to $10 \mathrm{MPa}$, using a pressure controller (ER 3000, Tescom) regulating the pressure in the cell with a precision of $2 \%$ rel. The volume of the sample chamber in the center of the cell body is about $550 \mu \mathrm{l}$. A transparent quartz window (diameter $18 \mathrm{~mm}$ ) allows for microscopic observation of the processes in the sample chamber and the in situ Raman spectroscopic investigations.
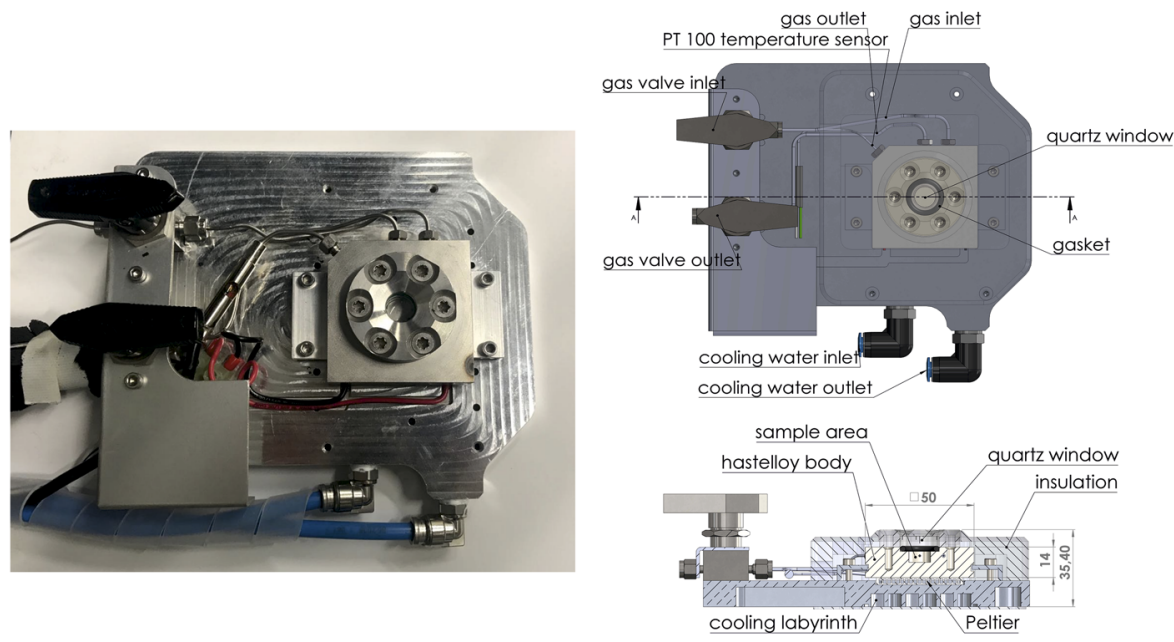

FIG. 1. Picture of the pressure cell (left) as well as a sketch of the pressure cell from a top view (top right) and side view (bottom right). Dimensions are given in $\mathrm{mm}$. 
The bottom of the cell body is used for cooling with a Peltier cooler (Laird Technologies, Typ CP1.4-127-045L). For the temperature control, a process controller (ESM-4450.1.20.1.1 from EMKO) is employed. In combination with an operational amplifier (OPA549 from Texas instruments) and a $20 \mathrm{~V} / 10$ A power supply, the controller works as a current source for the Peltier element. Water cooling of the Peltier element results in an efficient heat dissipation. This allows for a fast and precise cooling of the complete cell body with defined cooling rates where the desired temperature can be adjusted with a precision of $0.1 \mathrm{~K}$. The temperature of the sample is measured with a PT 100 temperature sensor. Temperature gradients can be neglected due to the small volume of the sample area and the complete cooling of the cell body. A special feature of the pressure cell is the continuous gas flow. The gas flow is measured and regulated in the complete pressure range of the pressure cell with a commercial flowmeter (Bronkhorst HI-TEC digital mass flow controller F230M-AAD-11-K). A supply line with a diameter of max. $1.6 \mathrm{~mm}$ and a length of $45 \mathrm{~mm}$ for the feed gas was drilled into the cell body to allow for the pre-cooling of the feed gas flow before entering the sample area. If the composition of the feed gas phase has to be changed, a valve located between two gas bottles with the specific gases or certified gas mixtures has to be adjusted. Two additional valves at the gas entry and the exit of the pressure cell can be closed to interrupt the gas flow. Figure 2 shows the sketch of the experimental setup.

\section{Experimental procedure}

The experiment starts with the preparation of the pressure cell. For this purpose, the pressure cell and all supply lines are first flushed with the respective gas or gas mixture for about $1 \mathrm{~h}$ with a gas flow of $1 \mathrm{ml} / \mathrm{min}$. Thereafter, $150 \mu \mathrm{l}$ of deionized and degassed water are filled into the sample cell. The cell is carefully sealed and flushed again with the respective gas or gas mixture to avoid contamination with air. Afterward, within around $60 \mathrm{~s}$, the pressure is set above the equilibrium pressure at the given temperature of the expected hydrate phase. When the final pressure is reached and the flow rate of the gas is constant, the cell is cooled down to $253 \mathrm{~K}$ with $\sim 2 \mathrm{~K} / \mathrm{min}$ to induce the spontaneous crystallization of hydrate and ice. The growth of both ice and gas hydrate crystals can be observed over time via optical microscopy through the quartz window. Subsequently, the cell is slowly warmed up to allow dissociation of ice and most hydrate crystals until there are only a few hydrate crystals left. Then, the cell is cooled down again to a temperature below the equilibrium temperature of the hydrate phase at the given pressure, but above the melting temperature of ice. Under these set conditions, euhedral gas hydrate crystals are allowed to grow. The "melting-cooling" process is carried out three times before the temperature at the given pressure is fixed at $274.15 \mathrm{~K}$.

As an alternative hydrate formation process, $100 \mu \mathrm{l}$ of fine grained ice is filled into the pre-cooled pressure cell. The ice is prepared from deionized water frozen in a liquid nitrogen bath and milled in a 6750 Freezer Mill (SPEX CertiPrep) to obtain a fine ice powder. ${ }^{27}$ The pressure cell is carefully sealed and flushed with the respective gas or gas mixture. Thereafter, the cell is pressurized at a temperature below the ice melting point and the transformation of the ice into a hydrate phase can be immediately observed. Special attention has to be paid to gas mixtures containing higher hydrocarbons or $\mathrm{CO}_{2}$ to ensure that none of the gas components condenses directly from the feed gas.

To investigate the hydrate formation process with different gas supply conditions, two valves at the gas inlet and outlet are either open to simulate a continuous gas flow or closed to simulate an interrupted gas flow. Within these experiments, the coordinates of several selected hydrate crystals are detected for continuous Raman measurements during the following days. With this approach, the selected crystals can be determined over the entire duration of the experiment of several days since the motorized stage allows for the positioning of the sample cell at defined coordinates. In order to obtain further information on the spatial distribution of the encased gas molecules in the hydrate phase, various larger euhedral crystals can be selected for hyperspectral mapping. During

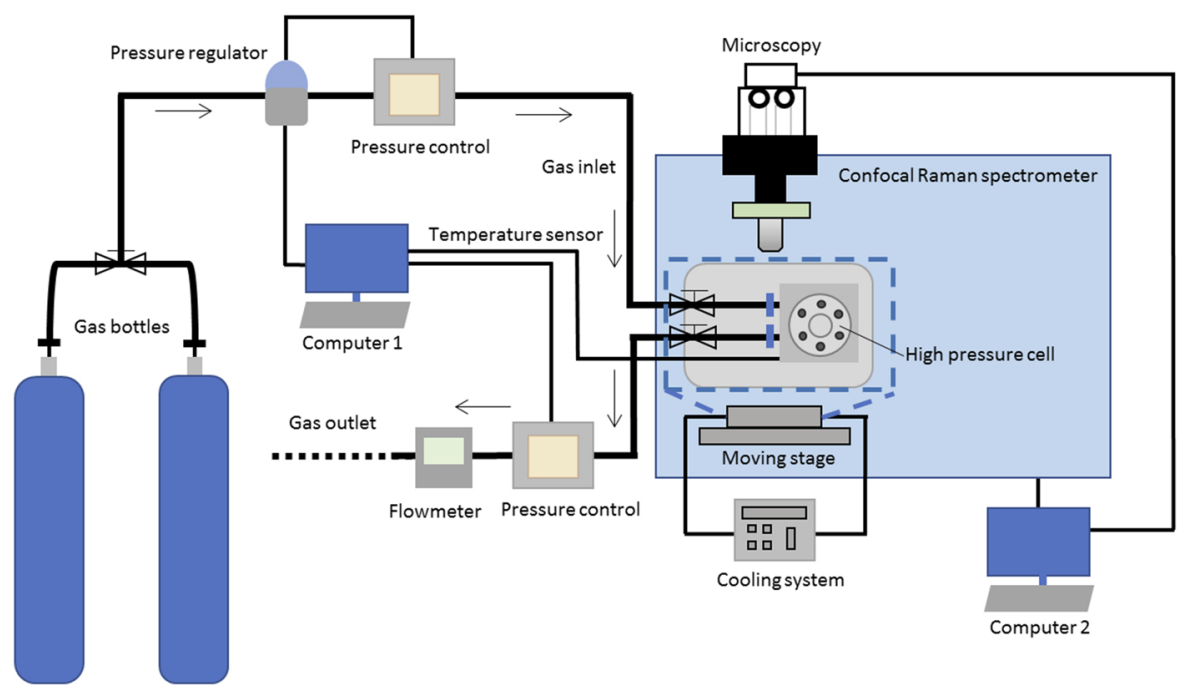

FIG. 2. Technical sketch of the experimental setup. 
the mapping process, the chosen area is scanned automatically step by step in one direction for line mapping and both $\mathrm{x}-\mathrm{y}$ directions for area mapping following a software-controlled measurement protocol.

To mimic fluctuations in the feed gas composition and to investigate the potential resulting transformation of hydrates, the feed gas composition can be changed, e.g., from the initial hydrate-forming gas to a gas or gas mixture with a different composition without any changes in pressure and temperature. For this purpose, a valve located between two gas bottles with the specific gases or certified gas mixtures must be adjusted. Continuous Raman measurements of the gas phase and the hydrate crystals allow the entire conversion process to be tracked.

\section{DATA ANALYSIS AND PRELIMINARY RESULTS}

Determination of the (heterogeneous) composition of the hydrate phases formed from complex gas mixtures or during a transformation process using Raman spectroscopy is demonstrated in this section. Before the experiment, important Raman instrumental parameters, which could affect the resulting spectra, were tested and optimized over the same sample spot to eliminate artifacts associated with the heterogeneity of the sample. For instance, the effect of the incident power of the laser beam was studied for $532 \mathrm{~nm}$ wavelength. The power at the sample was adjusted via neutral density filters that result in $25 \%, 50 \%, 75 \%$, and $100 \%$ of the output laser power. Among the tested intensities, a $100 \%$ intensity was selected for the experiment since it provides the best signal-to-noise ratio while laser irradiation damage at the sample was not observed. With these conditions, the laser power at the sample surface is $\sim 48 \mathrm{~mW}$. For this specific case, the pinhole size was defined at $50 \mu \mathrm{m}$, which offers best spatial resolution. The exposure time and the number of exposures were optimized to gain best signal-to-noise ratios according to optimal total measurement times. For this experimental setup, acquisition times of $5 \mathrm{~s}$ and 2 averaged exposures were chosen.

For the experiment, a gas hydrate phase was synthesized in the new high-pressure cell from water and a certified gas mixture containing 79 mol. \% $\mathrm{CH}_{4}, 8$ mol. $\% \mathrm{C}_{2} \mathrm{H}_{6}, 11$ mol. \% $\mathrm{C}_{3} \mathrm{H}_{8}, 1 \mathrm{~mol}$. $\%$ iso- $\mathrm{C}_{4} \mathrm{H}_{10}$, and $1 \mathrm{~mol} \% n-\mathrm{C}_{4} \mathrm{H}_{10}$ at $2.2 \mathrm{MPa}$ and $274 \mathrm{~K}$ using a continuous gas flow. This complex gas mixture was chosen because these components were detected in gas hydrate deposits in the Qilian Mountain region. Since a mixture of many different hydrocarbons often also poses a challenge for analysis by means of Raman spectroscopy, this gas mixture is most suitable for this rather methodical proof-of-concept study presented here.

In addition to the hydrate formation using the continuous gas flow, a parallel test was also carried out under identical $\mathrm{p}-\mathrm{T}$ conditions but with the inlet and outlet valves being closed to mimic a closed system. In both experiments (with and without using the continuous gas flow), selected hydrate crystals were regularly characterized at the crystal surface with single point Raman measurements during the formation process. Additional Raman measurements were taken at different depths from the surface of the crystal to $120 \mu \mathrm{m}$ below the crystal surface to find out when the hydrate crystals reached a steady state during this process. For this purpose, the laser beam was first focused on the surface of the hydrate crystal; subsequently, the position of the motorized sample stage was varied vertically ( $\mathrm{z}$ direction) in $30 \mu \mathrm{m}$ steps in such a way that the focus of the laser beam moved into the hydrate crystal. The Raman spectra measured at the defined depths and over time indicate that it took typically 5 days -6 days until the hydrate composition reached a steady state through the hydrate crystals. For further analysis of data, however, we only refer to the Raman spectra measured on the surface of the hydrate crystals.

Since the integrated Raman band area of each component is proportional to the number of molecules present in the probed volume of the sample, the comparison of the relative band integralareas of the species permits estimation of their relative abundance in the crystal structure and, hence, may be used for a semi-quantitative determination of the composition of the hydrate crystal at each measuring point. For the determination of the band areas in the Raman spectra, the software package Labspec 6.5 was used. Gauss/Lorentz functions were fitted to the observed Raman bands after an appropriate background correction. This software also offers an automatic correction of the instrument efficiency. After determination of the peak area from the spectra, this integral has to be corrected with a cross section factor of the respective component to determine a semi-quantitative composition of the sample. This procedure for the semi-quantitative determination of the hydrate composition based on the analysis of the Raman data is described elsewhere in more detail. $^{28}$

Figure 3 shows the changes in average composition in the hydrate phase based on single point measurements conducted at the surfaces of 12 selected hydrate crystals and the encasement of the different components into the hydrate phase during the first $76 \mathrm{~h}$
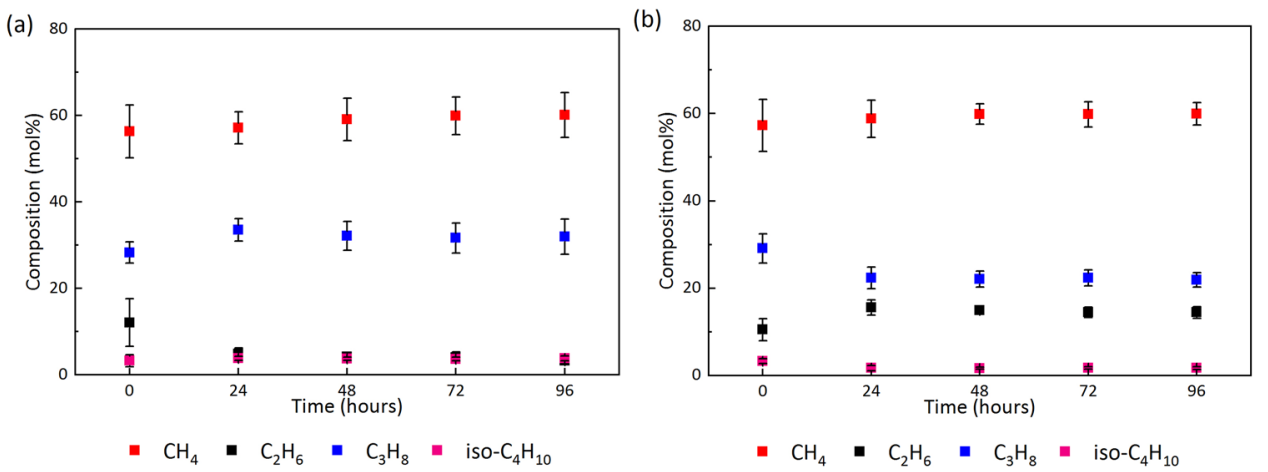

FIG. 3. Average compositional changes measured on the surfaces of 12 selected hydrate crystals during the hydrate formation process as obtained by in situ Raman spectroscopic measurements in the open system [Fig. 3(a)] and in the closed system [Fig. 3(b)]. 


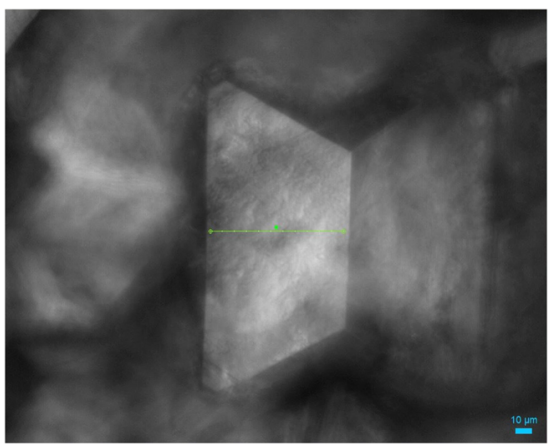

FIG. 4. Reflected-light photomicrograph of one mixed gas hydrate crystal within the sample chamber formed from a gas mixture containing $\mathrm{CH}_{4}, \mathrm{C}_{2} \mathrm{H}_{6}, \mathrm{C}_{3} \mathrm{H}_{8}$, iso$\mathrm{C}_{4} \mathrm{H}_{10}$, and $n-\mathrm{C}_{4} \mathrm{H}_{10}$ in the open system. The green line indicates the position of the 12 measurement spots across the crystal.

in the open system [Fig. 3(a)] and in the closed system [Fig. 3(b)]. It turned out that $\mathrm{C}_{3} \mathrm{H}_{8}$ and iso- $\mathrm{C}_{4} \mathrm{H}_{10}$ in the open system were enriched into the hydrate phase from the beginning of the formation process when compared to the corresponding concentrations of these components in the feed gas phase. This observation of the preferred encasement of $\mathrm{C}_{3} \mathrm{H}_{8}$ and iso- $\mathrm{C}_{4} \mathrm{H}_{10}$ into the hydrate phase is in good agreement with the observations of Uchida et al. ${ }^{15}$ However, the forming hydrate phase in the closed system [Fig. 3(b)] revealed a different composition compared to the hydrate phase formed in the open system. It turned out that the average concentration of $\mathrm{C}_{2} \mathrm{H}_{6}$ was higher, while the concentration of $\mathrm{C}_{3} \mathrm{H}_{8}$ was lower in the hydrate phase formed in the closed system. The result indicates that a limited amount of gas leads to the enclathration of those components, which are not preferred in the open system (e.g., $\mathrm{C}_{2} \mathrm{H}_{6}$ ). Unfortunately, the Raman band of $n-\mathrm{C}_{4} \mathrm{H}_{10}$ in the hydrate phase $\left(838 \mathrm{~cm}^{-1}\right)$ was either not detectable or showed such low intensities that these data could not be used for a semi-quantitative evaluation. Thus, $n-\mathrm{C}_{4} \mathrm{H}_{10}$ was excluded from Fig. 3.

After the hydrate crystals reached a steady state in the open system where no changes were observed over time, a line scan was conducted with 12 Raman measurement points across the surface of one selected crystal shown in Fig. 4.

The line scan measurement on the identical crystal was repeated three times in the open system. Figure 5 shows the respective Raman spectra taken at one defined measurement spot of the line scan during the three runs demonstrating the high reproducibility of the Raman measurements with respect to the composition of the hydrate crystal at that specific spot and the measuring range of the motorized sample stage. Raman bands were assigned as listed in Table I according to literature data.

Figure 6 shows the average values for the composition of the hydrate crystal at each measuring point and the respective standard deviation from three repeated line scans in the open system. The results show an excellent reproducibility, which, in turn, indicate that the measured variations in the local composition of the hydrate crystal demonstrate the non-stoichiometric and inhomogeneous character of hydrate crystals. As mentioned before, the Raman band of $n-\mathrm{C}_{4} \mathrm{H}_{10}$ in the hydrate phase $\left(838 \mathrm{~cm}^{-1}\right)$ was either not detectable or showed such low intensities that these data could not be used for the determination of the $n-\mathrm{C}_{4} \mathrm{H}_{10}$ proportion in the hydrate phase. It should be noted that the low enclathration of $n-\mathrm{C}_{4} \mathrm{H}_{10}$ into the hydrate phase was not unexpected. Since the linear $n-\mathrm{C}_{4} \mathrm{H}_{10}$ can only be incorporated into the large cages of a structure II hydrate in its gauche conformation, which nevertheless leads to distortions of the cage structure, smaller and more spherical guest molecules are preferred for the enclathration into the hydrate phase. ${ }^{32}$

The inhomogeneous nature of hydrates becomes even clearer when an area of a certain crystal was analyzed. Figure 7 (a) shows the measured area of about $50 \times 60 \mu \mathrm{m}^{2}$ on the surface of a hydrate crystal and the 35 measuring points within this area in the open system. Depending on the roughness and/or inclination of the crystal surface, the surface can be analyzed either as is or the topography of the surface must be determined using the special software "ViewSharp." Based on this topographic profile, the system focuses automatically on the crystal surface to ensure that all Raman spectra taken were focused on the surface and not above or below (see also Sec. II).
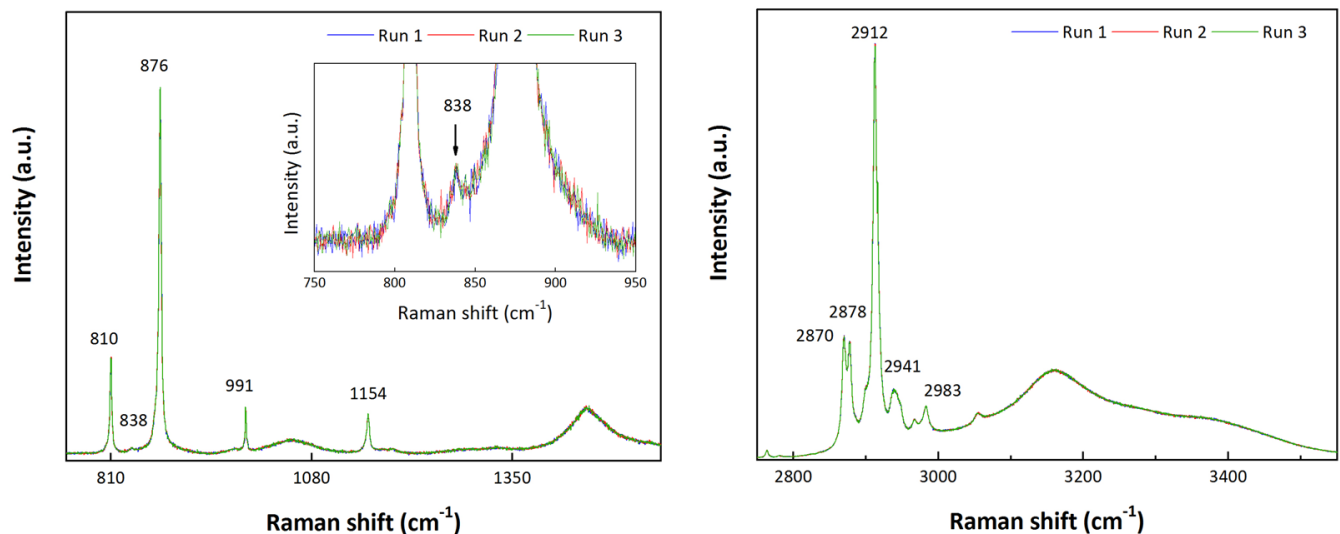

FIG. 5. Raman spectra taken at the same defined measurement spot on the surface of one hydrate crystal during the three runs of the line scan. Left: Raman spectra taken in the range of $750 \mathrm{~cm}^{-1}-1500 \mathrm{~cm}^{-1}$. Right: Raman spectra taken in the range of $2750 \mathrm{~cm}^{-1}-3550 \mathrm{~cm}^{-1}$. 
TABLE I. Assignment of measured Raman bands of different types of gas molecules encased into the hydrate structure based on literature data.

\begin{tabular}{|c|c|c|c|c|}
\hline Molecule & Vibrational mode & Measured data $\left(\mathrm{cm}^{-1}\right)$ & Literature data $\left(\mathrm{cm}^{-1}\right)$ & References \\
\hline $\mathrm{CH}_{4}$ & $\mathrm{C}-\mathrm{H}$ stretching & 2912 & 2913 & Sum et al. ${ }^{9}$ \\
\hline \multirow[t]{2}{*}{$\mathrm{C}_{2} \mathrm{H}_{6}$} & $\mathrm{C}-\mathrm{C}$ stretching & 991 & 992 & Kumar et al. ${ }^{29}$ \\
\hline & $\mathrm{C}-\mathrm{H}$ stretching & 2941 & 2940 & Uchida et al. ${ }^{15}$ \\
\hline \multirow[t]{5}{*}{$\mathrm{C}_{3} \mathrm{H}_{8}$} & $\mathrm{C}-\mathrm{C}$ stretching & 876 & 876 & Uchida et al. ${ }^{15}$ \\
\hline & $\mathrm{CH}_{3}$ rocking & 1154 & 1157 & Kumar et al. ${ }^{29}$ \\
\hline & C-H stretching & 2870 & 2870 & Uchida et al. ${ }^{12}$ \\
\hline & & 2878 & 2878 & Uchida et al. ${ }^{12}$ \\
\hline & $\mathrm{CH}_{2}$ stretching & 2983 & 2983 & Schicks et al. ${ }^{30}$ \\
\hline iso- $\mathrm{C}_{4} \mathrm{H}_{10}$ & $\mathrm{C}-\mathrm{C}$ stretching & 810 & 811 & Uchida et al..$^{15}$ \\
\hline$n-\mathrm{C}_{4} \mathrm{H}_{10}$ & $\mathrm{C}-\mathrm{C}$ stretching & 838 & 837 & Subramanian and Sloan ${ }^{31}$ \\
\hline
\end{tabular}

After finishing the mapping of the hydrate surface area, each particular Raman spectrum can be analyzed individually to determine the composition of the hydrate crystal at each specific point as described above. Since this is extensive work, in particular, if the number of measuring points in the Raman maps is higher than in our example, an automatic data processing is desirable. Therefore, the LabSpec 6.5 software also offers the opportunity to carry out automated baseline corrections and the calculation of the band integral-area for all spectra and to display the generated data for each component in a color-coded map. Figure 7(b) shows the value of the band integral-area in a color code for $\mathrm{C}_{3} \mathrm{H}_{8}$. The absolute values of each measuring point depicted as a pixel in the map can be read out and transferred to other programs, such as Excel. These values can also be processed and, e.g., corrected with the respective cross section factors of each component.

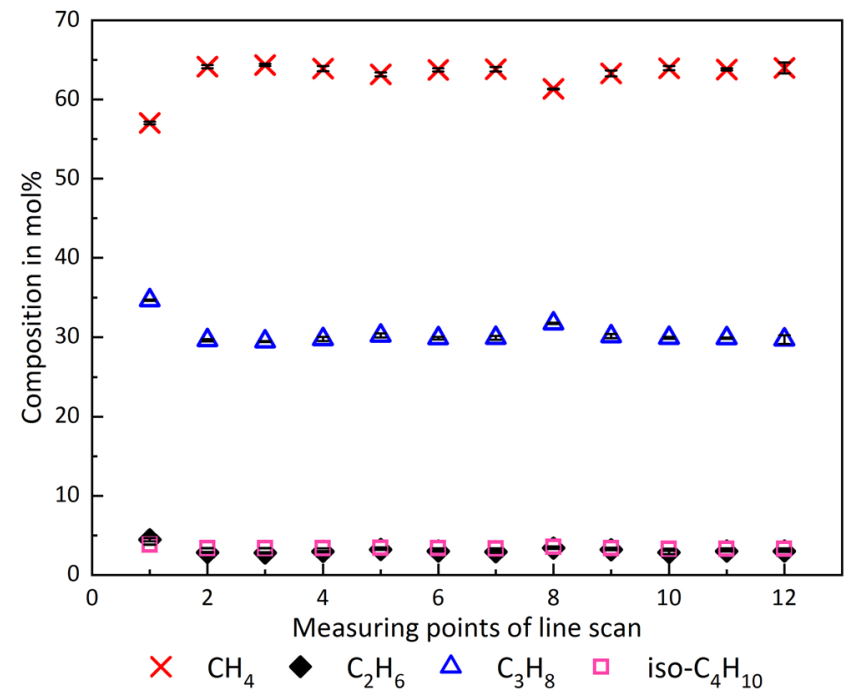

FIG. 6. Mean values for the different components encased into the hydrate at each of the twelve measuring points across the crystal (see Fig. 4). The error bars indicate the standard deviation. Since the values for $\mathrm{C}_{2} \mathrm{H}_{6}$ and iso- $\mathrm{C}_{4} \mathrm{H}_{10}$ are in the same range, the data points and error bars overlap.
In order to verify the quality of the automatic data process options within the LabSpec 6.5 software, we chose the Raman bands of $\mathrm{CH}_{4}, \mathrm{C}_{2} \mathrm{H}_{6}$, and $\mathrm{C}_{3} \mathrm{H}_{8}$ and compared the results of an automatic data processing with the individual analysis of the Raman spectra. For this purpose, the Raman map of the hydrate crystal with $35(7 \times 5)$ measuring points was used. It turned out that the values of the automatically calculated Raman band areas differ from the values we got when every spectrum from each related measuring point was analyzed manually. When the Raman spectra were analyzed manually, in each spectrum, the baseline function was adapted individually and adjusted to the spectrum to find an optimal correction. For the automatic analysis, however, one defined baseline function is applied to all spectra, which may result in some cases in a less optimal correction and may cause deviations between manually and automatically generated integrated Raman band areas. For Raman bands with a high intensity and a high integrated area $\left(>10000 \mathrm{~cm}^{-1} \times\right.$ counts), in our case $\mathrm{CH}_{4}$, the statistical deviation between the manually and automatically analyzed peak areas is only about $2 \%$ rel., and therefore, this statistical error can be neglected. However, for those Raman bands with smaller intensities and integrated band areas $\left(<10000 \mathrm{~cm}^{-1}\right.$ $\times$ counts) - in our case $\mathrm{C}_{3} \mathrm{H}_{8}$ - the deviations between manually and automatically calculated values for the peak area are between $5 \%$ and $10 \%$. It becomes even worse for Raman bands with very small intensities and integrated areas $\left(<1000 \mathrm{~cm}^{-1} \times\right.$ counts $)$, such as $\mathrm{C}_{2} \mathrm{H}_{6}$ in our experiment. Here, the deviation between manually and automatically calculated values for the integrated Raman band areas can be up to $25 \%$ rel. In these cases, the interpretation of the data is highly affected by the pre-selected data-treatment method.

However, for the depiction of the variation in the composition of the hydrate crystal, it is also possible to calculate the ratio of two specific components, e.g., $\mathrm{C}_{2} \mathrm{H}_{6}$ and $\mathrm{C}_{3} \mathrm{H}_{8}$. In this case, the areas of the Raman bands at $991 \mathrm{~cm}^{-1}$ for $\mathrm{C}_{2} \mathrm{H}_{6}$ and $876 \mathrm{~cm}^{-1}$ for $\mathrm{C}_{3} \mathrm{H}_{8}$ can optionally be corrected with or without a baseline, e.g., using the tool "Map Characterization" of the LabSpec 6.5 software. Figure 8 shows the variation of $\mathrm{C}_{2} \mathrm{H}_{6} / \mathrm{C}_{3} \mathrm{H}_{8}$ ratio with baseline correction [Fig. 8(a)] and without baseline correction [Fig. 8(b)]. Increasing brightness reflects a higher $\mathrm{C}_{2} \mathrm{H}_{6} / \mathrm{C}_{3} \mathrm{H}_{8}$ ratio, whereas darker points represent a lower $\mathrm{C}_{2} \mathrm{H}_{6} / \mathrm{C}_{3} \mathrm{H}_{8}$ ratio. 

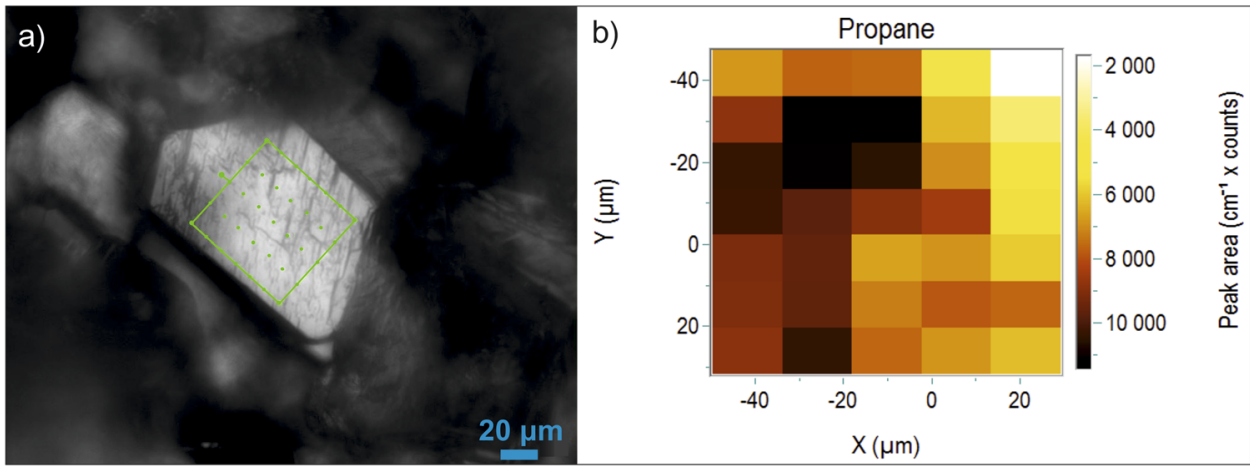

FIG. 7. (a) Scanned area on a hydrate crystal surface in the open system. 5 $\times 7$ measuring points were chosen to analyze the composition of the hydrate crystal. (b) Variation of the $\mathrm{C}_{3} \mathrm{H}_{8}$ band integral-area at $876 \mathrm{~cm}^{-1}$ indicating the $\mathrm{C}_{3} \mathrm{H}_{8}$ content in the hydrate crystal surface in the mapped area. Darker points reflect a higher $\mathrm{C}_{3} \mathrm{H}_{8}$ content, whereas brighter points represent a lower $\mathrm{C}_{3} \mathrm{H}_{8}$ content.
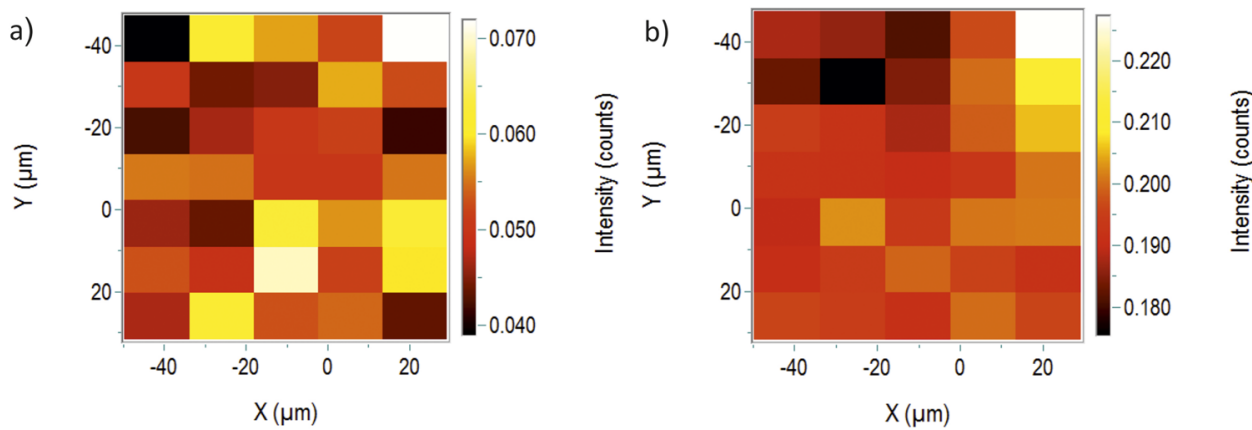

FIG. 8. Results for the calculated variation of the $\mathrm{C}_{2} \mathrm{H}_{6} / \mathrm{C}_{3} \mathrm{H}_{8}$ ratio in the mapped area when baseline correction was applied [Fig. 8(a)] and without baseline correction [Fig. 8(b)].

Figures 8(a) and 8(b) clearly demonstrate that the application of the baseline correction tool leads to completely different results. In our case, the results after baseline correction are in better agreement with manually calculated data from Raman spectra. Nevertheless, the examples show that care has to be taken if an automatic processing of the mapping data has to be applied.

The spatial resolution can be much higher than chosen in this experiment. Depending on the used objective, the maximum spatial resolution in the $\mathrm{x}-\mathrm{y}$ direction may reach $\sim 0.5 \mu \mathrm{m}$; however, the input of energy due to the laser beam is not negligible and may destroy the temperature-sensitive gas hydrate crystals. Therefore, the chosen number of measuring points within the mapping area should be high enough to provide sufficient data to identify heterogeneities and transitions to coexisting phases, but also low enough to avoid a dissociation of the hydrate phase due to the high energy impact from the laser beam.

Apart from the above-mentioned formation process, the pressure cell is also applicable for the investigation of a transformation process on a micrometer scale. For this purpose, a pure $\mathrm{CH}_{4}$ hydrate was first synthesized following the same procedures as described above. After the pure $\mathrm{CH}_{4}$ hydrate reached a steady state, the valve between two gas bottles was adjusted to change the feed gas from initial $\mathrm{CH}_{4}$ gas to pure $\mathrm{CO}_{2}$ gas at a constant temperature and pressure condition. Continuous Raman measurements were performed on the gas phase and hydrate phase to investigate the transformation process.

It is shown from Fig. 9 that the $\mathrm{CO}_{2}$ proportion in the gas phase increased dramatically within the first $500 \mathrm{~min}$ after the feed gas was changed $(0 \mathrm{~min})$. Thereafter, the gas exchange slowed down until almost $100 \% \mathrm{CO}_{2}$ was detected in the gas phase. The compositional change in the hydrate phase was faster in the first 2 days after the exchange of the feed gas phase compared to the conversion rate that was recorded thereafter. Finally, the average composition of the

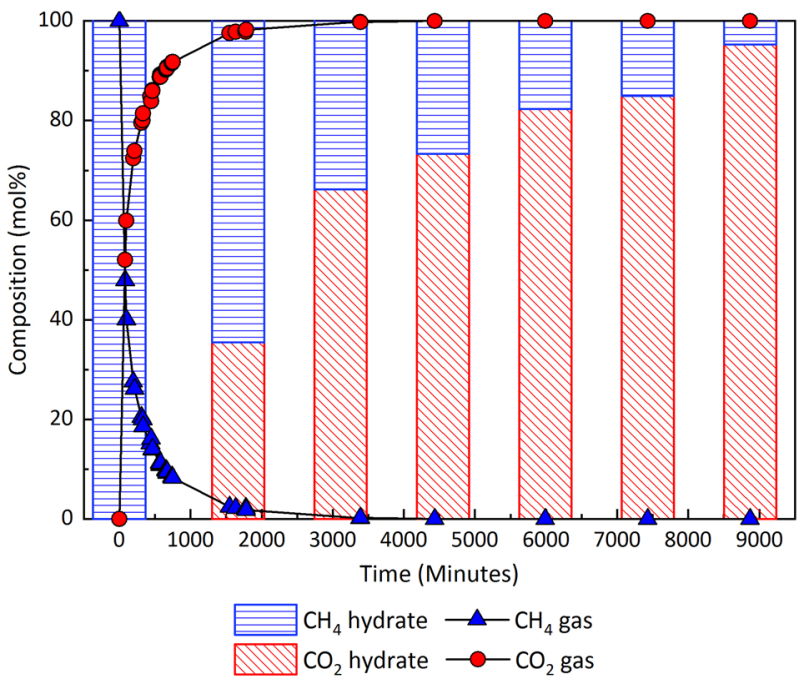

FIG. 9. Average molar composition changes of 15 selected hydrate crystals indicating the transformation process of pure $\mathrm{CH}_{4}$ hydrate to $\mathrm{CO}_{2}$-rich mixed hydrates when the feed gas phase was shifted from pure $\mathrm{CH}_{4}$ gas to pure $\mathrm{CO}_{2}$ gas. The blue triangles and red circles illustrate the composition of $\mathrm{CH}_{4}$ and $\mathrm{CO}_{2}$ in the gas phase, respectively, whereas the bars indicate the composition of the hydrate phase (red- $\mathrm{CO}_{2}$ and blue- $-\mathrm{CH}_{4}$ ) 
mixed $\mathrm{CH}_{4}-\mathrm{CO}_{2}$ hydrate was around $90 \mathrm{~mol} . \% \mathrm{CH}_{4} / 10$ mol. $\% \mathrm{CO}_{2}$ after more than 6 days.

\section{SUMMARY}

The experimental setup presented here was developed for the investigation of complex gas hydrate formation and transformation processes. It consists of a high-resolution Raman spectrometer combined with a confocal microscope and a specially designed high-pressure cell. This setup allows for in situ determination of the composition of the gas hydrate phase during the formation process and after a steady state was reached as well as transformation processes as a response to environmental changes of the hydrate phase, such as changes in gas composition, temperature, or pressure. The in situ determination of the composition and cage occupancies of the gas hydrate phase can be achieved with single point measurements, line scans, and area maps providing information on the molecular enclathration processes during the formation as well as the heterogeneity of the resulting hydrate phase. The high spatial resolutions of the line scans and area maps together with the high reproducibility and accuracy of the motorized and software-controlled sample stage allow for a precise characterization in $\mathrm{x}-\mathrm{y}$ and $\mathrm{z}$ directions.

\section{ACKNOWLEDGMENTS}

The authors thank the staff of the GFZ workshops for invaluable technical help and for the construction of the pressure cell. Mengdi Pan thanks the China Scholarship Council program for the financial support (Grant No. 201704910817). Nur Aminatulmimi Ismail acknowledges the financial support received from the Deutscher Akademischer Austauschdienst (DAAD) Scholarship.

\section{DATA AVAILABILITY}

The data that support the findings of this study are available within the article.

\section{REFERENCES}

${ }^{1}$ M. von Stackelberg, O. Götzen, J. Pietuchovsky, O. Witscher, H. Frühbuss, and W. Meinhold, "Struktur und Formel der Gashydrate," Fortschr. Mineral. 26, 122-124 (1947).

${ }^{2}$ H. Lu, Y.-T. Seo, J.-W. Lee, I. Moudrakovski, J. A. Ripmeester, N. R. Chapman, R. B. Coffin, G. Gardner, and J. Pohlman, "Complex gas hydrate from the Cascadia margin," Nature 445, 303-306 (2007).

${ }^{3}$ S. A. Klapp, M. M. Murshed, T. Pape, H. Klein, G. Bohrmann, P. G. Brewer, and W. F. Kuhs, "Mixed gas hydrate structures at the Chapopote Knoll, southern Gulf of Mexico," Earth Planet. Sci. Lett. 299, 207-217 (2010).

${ }^{4}$ S. A. Klapp, G. Bohrmann, W. F. Kuhs, M. M. Murshed, T. Pape, H. Klein, K. S. Techmer, K. U. Heeschen, and F. Abegg, "Microstructures of structure I and II gas hydrates from the Gulf of Mexico," Mar. Pet. Geol. 27, 116-125 (2010).

${ }^{5}$ J. Wei, Y. Fang, H. Lu, H. Lu, J. Lu, J. Liang, and S. Yang, "Distribution and characteristics of natural gas hydrates in the Shenhu Sea Area, South China Sea," Mar. Pet. Geol. 98, 622-628 (2018)

${ }^{6}$ Y. Jin, M. Kida, J. Yoneda, Y. Konno, N. Tenma, M. Oshima, and J. Nagao, "Natural gas hydrates recovered from the Umitaka Spur in the Joetsu Basin, Japan: Coexistence of two structure-I hydrates with distinctly different textures and gas compositions within a massive structure," ACS Earth Space Chem. 4, 77-85 (2020).
${ }^{7}$ A. Y. Manakov, O. M. Khlystov, A. Hachikubo, K. Minami, S. Yamashita, A. Khabuev, A. G. Ogienko, A. V. Ildyakov, G. V. Kalmychkov, and T. V. Rodionova, "Structural studies of Lake Baikal natural gas hydrates," J. Struct. Chem. 60(9), 1437-1455 (2019).

${ }^{8}$ Y. Hiraga, T. Sasagawa, S. Yamamoto, H. Komatsu, M. Ota, T. Tsukada, and R. L. Smith, Jr., "A precise deconvolution method to derive methane hydrate cage occupancy ratios using Raman spectroscopy," Chem. Eng. Sci. 214, 115361 (2020).

${ }^{9}$ A. K. Sum, R. C. Burruss, and E. D. Sloan, Jr., "Measurement of clathrate hydrates via Raman spectroscopy,” J. Phys. Chem. B 101, 7371-7377 (1997).

${ }^{10} \mathrm{~S}$. Subramanian and E. D. Sloan, Jr., "Molecular measurements of methane hydrate formation," Fluid Ph. Equilibria. 158-160, 813-820 (1999).

${ }^{11}$ C. A. Tulk, J. A. Ripmeester, and D. D. Klug, "The application of Raman spectroscopy to the study of gas hydrates," Ann. N. Y. Acad. Sci. 912(1), 859-872 (2000).

${ }^{12}$ T. Uchida, M. Moriwaki, S. Takeya, I. Y. Ikeda, R. Ohmura, J. Nagao, H. Minagawa, T. Ebinuma, H. Narita, K. Gohara, and S. Mae, "Two-step formation of methane-propane mixed gas hydrates in a batch-type reactor," AIChE J. 50(2), 518-523 (2004).

${ }^{13}$ J. M. Schicks, M. A. Ziemann, H. Lu, and J. A. Ripmeester, "Raman spectroscopic investigations on natural samples from the Integrated Ocean Drilling Program (IODP) Expedition 311: Indications for heterogeneous compositions in hydrate crystals," Spectrochim. Acta A 77, 973-977 (2010).

${ }^{14}$ M. Luzi-Helbing, J. Prinz, I. Bald, and J. M. Schicks, "Investigation of heterogeneously composed gas hydrates via Raman mapping," in Proceedings of the 9th International Conference on Gas Hydrates, Denver, USA, 2017.

${ }^{15}$ T. Uchida, S. Takeya, Y. Kamata, R. Ohmura, and H. Narita, "Spectroscopic measurements on binary, ternary, and quaternary mixed-gas molecules in clathrate structures,” Ind. Eng. Chem. Res. 46(14), 5080-5087 (2007).

${ }^{16}$ J. M. Schicks and M. Luzi-Helbing, "Kinetic and thermodynamic aspects of clathrate hydrate nucleation and growth," J. Chem. Eng. Data 60, 269-277 (2015).

${ }^{17}$ A. Hachikubo, O. Khlystov, A. Manakov, M. Kida, A. Krylov, H. Sakagami, H. Minami, N. Takahashi, H. Shoji, G. Kalmychkov, and J. Poort, "Model of formation of double structure gas hydrates in Lake Baikal based on isotopic data," Geophys. Res. Lett. 36, L18504, https://doi.org/10.1029/2009gl039805 (2009).

${ }^{18}$ A. Y. Manakov, O. M. Khlystov, A. Hachikubo, and A. G. Ogienko, “A physicochemical model for the formation of gas hydrates of different structural types in K-2 mud volcano (Kukui Canyon, Lake Baikal)," Russ. Geol. Geophys. 54, 475-482 (2013).

${ }^{19}$ Z. Huo, K. Hester, E. D. Sloan, Jr., and K. T. Miller, "Methane hydrate nonstoichiometry and phase diagram," AIChE J. 49(5), 1300-1306 (2003).

${ }^{20}$ M. Celli, M. Zoppi, M. A. S. Zaghloul, and L. Ulivi, "High pressure optical cell for synthesis and in situ Raman spectroscopy of hydrogen clathrate hydrates," Rev. Sci. Instrum. 83, 113101 (2012).

${ }^{21}$ H. J. Shin, Y.-J. Lee, J.-H. Im, K. W. Han, J.-W. Lee, Y. Lee, J. D. Lee, W.-Y. Jang, and J.-H. Yoon, "Thermodynamic stability, spectroscopic identification and cage occupation of binary $\mathrm{CO}_{2}$ clathrate hydrates," Chem. Eng. Sci. 64, 5125-5130 (2009).

${ }^{22}$ L. Ruffine, J. P. Donval, J. L. Charlou, A. Cremière, and B. H. Zehnder, "Experimental study of gas hydrate formation and destabilisation using a novel high-pressure apparatus,” Mar. Petrol. Geol. 27, 1157-1165 (2010).

${ }^{23}$ W. J. Lu, I. M. Chou, R. C. Burruss, and M. Z. Yang, "In situ study of mass transfer in aqueous solutions under high pressures via Raman spectroscopy: A new method for the determination of diffusion coefficients of methane in water near hydrate formation conditions," Appl. Spectrosc. 60(2), 122-129 (2006).

${ }^{24}$ I.-M. Chou, A. Sharma, R. C. Burruss, J. Shu, H.-k. Mao, R. J. Hemley, A. F. Goncharov, L. A. Stern, and S. H. Kirby, "Transformations in methane hydrates," Proc. Natl. Acad. Sci. U. S. A. 97(25), 13484-13487 (2000).

${ }^{25}$ H. Hirai, N. Takahara, T. Kawamura, Y. Yamamoto, and T. Yagi, "Structural changes and preferential cage occupancy of ethane hydrate and methane-ethane mixed gas hydrate under very high pressure," J. Chem. Phys. 129, 224503 (2008).

${ }^{26}$ Z. Wang, D. He, W. Zhang, W. Li, W. Li, J. Qin, L. Lei, Y. Zou, and X. Yang, "Portable high pressure sapphire anvil cell for gas hydrates research," Rev. Sci. Instrum. 81, 085102 (2010). 
${ }^{27}$ J. M. Schicks and M. Luzi-Helbing, "Cage occupancy and structural changes during hydrate formation from initial stages to resulting hydrate phase," Spectrochim. Acta A 115, 528-536 (2013).

${ }^{28}$ B. Beeskow-Strauch, J. M. Schicks, R. Naumann, and J. Erzinger, "The influence of $\mathrm{SO}_{2}$ and $\mathrm{NO}_{2}$ impurities on $\mathrm{CO}_{2}$ gas hydrate formation and stability," Chem. Eur. J. 17, 4376-4384 (2011).

${ }^{29}$ R. Kumar, P. Linga, I. Moudrakovski, J. A. Ripmeester, and P. Englezos, "Structure and kinetics of gas hydrates from methane/ethane/propane mixtures relevant to the design of natural gas hydrate storage and transport facilities," AIChE J. 54(8), 2132-2144 (2008)
${ }^{30}$ J. M. Schicks, R. Naumann, J. Erzinger, K. C. Hester, C. A. Koh, and E. D. Sloan, "Phase transitions in mixed gas hydrates: Experimental observations versus calculated data," J. Phys. Chem. B 110(23), 11468-11474 (2006).

${ }^{31}$ S. Subramanian and E. D. Sloan, "Trends in vibrational frequencies of guests trapped in clathrate hydrate cages," J. Phys. Chem. B 106, 4348-4355 (2002).

${ }^{32}$ M. Luzi, J. M. Schicks, R. Naumann, J. Erzinger, K. Udachin, I. Moudrakowski, J. A. Ripmeester, R. Ludwig, "Investigations on the influence of guest molecule characteristics and the presence of multicomponent gas mixtures on gas hydrate properties," in Proceedings of the 6th International Conference on Gas Hydrates, Vancouver, Canada, 2008. 